\title{
Immunogold method evidences that kinesin and myosin bind to and couple microtubules and actin filaments in lipotubuloids of Ornithogalum umbellatum ovary epidermis
}

\author{
Maria Kwiatkowska $\cdot$ Justyna Teresa Polit • \\ Katarzyna Popłońska • Dariusz Stępiński • \\ Agnieszka Wojtczak
}

Received: 12 July 2012/Revised: 23 January 2013/Accepted: 30 January 2013/Published online: 27 February 2013

(C) The Author(s) 2013. This article is published with open access at Springerlink.com

\begin{abstract}
Lipotubuloids in ovary epidermis of Ornithogalum umbellatum which are a domain of cytoplasm containing a lot of lipid bodies, microtubules and actin filaments, ribosomes, endoplasmic reticulum as well as scarce mitochondria, microbodies, dictyosomes, autolytic vacuoles, exhibit progressive-rotary motion. The immunogold method demonstrated that microtubules and actin filaments of lipotubuloids might be connected with one another by myosin and kinesin. It was supposed that collaboration of motor proteins with actin filaments and microtubules makes autonomic high peripheral speed rotary motion of lipotubuloids in epidermis cells possible. Moreover, myosin was also detected in Golgi bodies in lipotubuloid. In lipotubuloids, the immunogold method demonstrated immunosignals after the use of an antibody to dynein light chains but spectroscopy mass analysis showed that in $O$. umbellatum epidermis lacked dynein heavy chains.
\end{abstract}

Keywords Actin filaments - Kinesin - Lipotubuloids · Microtubules $\cdot$ Myosin $\cdot$ Rotary motion

\section{Introduction}

In plant and animal cells, the cytoskeleton consists of two major networks of protein polymers, actin filaments and

Communicated by $\mathrm{H}$. Li.

M. Kwiatkowska $(\square) \cdot$ J. T. Polit · K. Popłońska ·

D. Stępiński · A. Wojtczak

Department of Cytophysiology, Faculty of Biology

and Environmental Protection, University of Łódź,

Pomorska 141/143, 90-236 Łódź, Poland

e-mail: kwiat@biol.uni.lodz.pl microtubules. However, classic intermediate filament proteins generating support in animal cells are absent from plant genomes (Collings 2009).

The cytoskeleton is involved in many fundamental cellular processes including morphogenesis, cell divisions and vesicle trafficking. It performs various functions with the assistance of interacting molecular motor proteins, signaling molecules or structure-supporting elements. Although actin filaments and microtubules fulfill many functions independently, they often act in a coordinated manner (Petrášek and Schwarzerowá 2009). Intracellular transport along actin filaments and microtubules depends on the associated motor proteins, myosins connected with actin filaments and kinesins and dyneins connected with microtubules. In higher plants, homologs of both myosins and kinesins are represented by gene families (Lee and Liu 2004), whereas dynein homologs are lacking in Arabidopsis (Lawrence et al. 2001). However, examination of the whole genome sequence of Oryza sativa has revealed that four dynein heavy chains are present in this monocot (King 2002). A high molecular weight polypeptide, cross-reacting with the antibodies to the dynein heavy chain, was also demonstrated in Triticum aestivum root meristem cells in the subset Golgi complex (Shanina et al. 2009). These results indicate that the apparent lack of dynein sequences in Arabidopsis is not a general feature of the angiosperm genomes.

Some evidence suggests that organelle movement and positioning involve interaction of microtubules, while the actomyosin system generates motility and reorientation of microtubules (Sainsbury et al. 2008). In animal cells, actinbased vesicle-transport motor, MyoVA, can interact directly with a microtubule-based transport motor, KhcU. Localization of MyoVA and KhcU overlaps in a cell (Huang et al. 1999). In animal cells, cross-talk between the 
mitotic actin cortex and plus ends of astral microtubules was demonstrated (Kunda and Baum 2009). In mouse melanoma cells (B16-F1), microtubules function as platforms for assaying actin polymerization in vivo (Oelkers et al. 2011).

Reports of actin filament and microtubule associations in plants are supported by imaging of fixed tissues, pharmacological studies and the existence of common binding partners. Localization of actin filaments on microtubular mitotic apparatus was demonstrated immunocytochemically in tobacco BY-2 cells (Yasuda et al. 2005). The structural cross-talk between actin and tubulin components was observed in the zone of distal elongation of Arabidopsis thaliana roots (Shevchenko 2009). A plant-specific kinesin binds to actin filaments and interacts with cortical microtubules in cotton fibers (Preuss et al. 2004), and in A. thaliana root cells (Collings et al. 2006). Dynamic bridges are a calponin-domain kinesin from rice which link actin filaments and microtubules in both cycling and non-cycling cells (Frey et al. 2009). SB401 pollen-specific protein from Solanum berthaultii binds to and couples microtubules and actin filaments (Huang et al. 2007). Kinesin GhKCH2 interacts with both microtubules and microfilaments in living plant cells of Arabidopsis protoplast as well as in biological processes they co-ordinate together in cotton cells (Xu et al. 2009). In Arabidopsis, the type II formin 14 interacts with microtubules and microfilaments and regulates cell divisions ( $\mathrm{Li}$ et al. 2010). Using spinning disc confocal microscopy in live cells of dual-labeled lines, coupled with pharmacological studies, it was deduced quantitatively that actin filaments and microtubules interact dynamically in A. thaliana (Sampathkumar et al. 2011).

The coalescence of short actin filaments and long microtubules was observed in ovary epidermis cells of $O$. umbellatum in EM microscopy (Kwiatkowska et al. 2005). These actin filaments, lying parallel to the surface of microtubules, are sensitive to cytochalasin $\mathrm{B}$ and are connected with rotary motion of lipotubuloids, i.e. a cytoplasmic domain containing aggregates of lipid bodies surrounded by microtubules which also include abundance of ribosome and endoplasmic reticulum, as well as single dictyosomes, mitochondria, microbodies and autolytic vacuoles (Kwiatkowska 1972; Kwiatkowska et al. 2009, 2012). Lipotubuloids do not have their own membrane but on the large area they are surrounded by a tonoplast as they invaginate into vacuoles. They move as one body because microtubules running in different directions surround and connect adjacent lipid bodies stabilizing their position.

Lipotubuloids were also observed in other plants: Haemantus albiflos (Kwiatkowska et al. 2010) Althaea rosea, Funkia Siebildiana, Vanilla planifolia (Kwiatkowska et al. 2011a).
In the present study, we examined the localization of motor proteins in lipotubuloids. We used the immunogold labeling method to identify motor proteins, kinesin and myosin as well as dynein light chains. The immunogold technique, first introduced to EM observation by Faulk and Taylor (1971), has been recently used to investigate motor proteins (Romagnoli et al. 2007; Lam et al. 2008; Wei et al. 2009; Brozzi et al. 2012; Lenartowska et al. 2012; Loubéry et al. 2012). Axons studied with double labeling immunogold technique showed preferential binding of a kinesin1 motor to GTP-tubulin-rich microtubules (Nakata et al. 2011).

Circulation of cytoplasm in ovary epidermis cell is multidirectional, different in each cytoplasm strand which led to the suggestion that it may be the source of lipotubuloid rotation, as they are surrounded by cytoplasm stream going in various directions. However, only the progressive movement of lipotubuloids depends on cyclosis, since its blockade with 2,4 dinitrofenol (DNP), which stops ATP synthesis, results in the blockade of this movement while consecutive 2-3 slowing down rotations of lipotubuloids can be observed during $90 \mathrm{~s}$ following cyclosis immobilization. Moment inertia may be ignored since the time for stopping the process, for bodies of this size order rotating in fluid, is only $10^{-7} \mathrm{~s}$ (Kwiatkowska 1972). This means that lipotubuloids have their own force driving rotation.

Using EM in planta, we demonstrated for the first time that myosin as well as kinesin bound to and mechanochemically coupled microtubules to actin filaments. Moreover, the Western blot indicated that dynein heavy chains were absent; however, the immunogold technique demonstrated the presence of dynein light chains in lipotubuloids of $O$. umbellatum epidermis.

\section{Materials and methods}

\section{Plant materials}

Ovary epidermis from fully developed flowers of $O$. umbellatum was used. The epidermal cells were in the phase of an intense elongation with a single lipotubuloid in each one.

Intracellular movement in $O$. umbellatum ovary epidermis

The observations in vivo were documented by means of film pictures at a frequency of 12 or 6 stills per second, which resulted in double or quadruple acceleration of the pictures of the motion during projection at a frequency of 24 stills per second. 
Electron microscopy

Ovary epidermis was fixed in the mixture of freshly prepared $2.5 \%$ glutaraldehyde and $1 \% \mathrm{OsO}_{4}(1: 1)$ in cacodylate buffer ( $\mathrm{pH} 7.4$ ) for $1 \mathrm{~h}$ and post fixed in $1 \% \mathrm{OsO}_{4}$ in the same buffer at $4{ }^{\circ} \mathrm{C}$ for $1 \mathrm{~h}$. After dehydration in the ethanol series, the material was embedded in the medium consisting of Epon 812 and Spurr's resin. Ultrathin sections cut using Reichert Jung Ultracut ultra microtome with a glass knife were double stained with uranyl acetate and lead citrate according to Reynolds (1963). The sections were examined and photographed in JEOL.JEM 1010 transmission electron microscope at $80 \mathrm{kV}$ acceleration voltage.

Immunogold technique

The plant material was prepared as it is described in EM section. Fixation only in the glutaraldehyde, which is recommended in immunogold technique, results in destruction of lipotubuloids and hence we added $1 \% \mathrm{OsO}_{4}$ to the fixative mixture. Freshly cut ultrathin sections were mounted on nickel Formvar coated grids for EM investigations. Prior to immunogold reaction, the sections were treated with $10 \%$ hydrogen peroxide for $15 \mathrm{~min}$ to remove osmium which changes antigen structure (Bendayan and Zollinger 1983) and washed in distilled water and PBS (0.01 M, pH 7.4, Sigma). Air-dried grids with four sections were blocked with $0.5 \%$ BSA and $0.05 \%$ Tween 20 in PBS for 20 min and then dried with tissue-paper and incubated with the primary rabbit polyclonal anti-kinesin antibody (Thermo Scientific, cat. number PA1-19392) or mouse monoclonal anti-myosin antibody, light chains $20 \mathrm{kDa}$ (Sigma, cat. number M4401) and goat polyclonal anti-dynein light chain (Santa Cruz Biotechnology, cat. number sc-15942) in antibody diluent (DAKO) 1:20 (kinesin, myosin) and 1:25 (dynein); overnight at $20^{\circ} \mathrm{C}$. Then, the grids were washed ten times for $5 \mathrm{~min}$ each in PBS and incubated with the secondary antibody goat anti-rabbit IgG conjugated with $10 \mathrm{~nm}$ gold (kinesin) or goat anti-mouse IgG conjugated with $20 \mathrm{~nm}$ gold (myosin) and rabbit anti-goat IgG conjugated with $10 \mathrm{~nm}$ gold (dynein) (no EM.GAR10, or EM.GMHL20 and EM.RAG10; Polysciences) diluted 1:50 in the antibody diluent for $1.5 \mathrm{~h}$ in the same temperature and rinsed again in PBS and distilled water (10 times for $5 \mathrm{~min}$ each). Ultrathin sections were double stained, examined and photographed as above.

\section{Double labeling immunogold technique}

Ovary epidermis was fixed as above. The plant material was prepared as it is described in EM section, and fixation was the same as described above.

Further steps were similar to the single labeling immunogold technique. The sections on grids were incubated overnight at $20{ }^{\circ} \mathrm{C}$ with the mouse monoclonal anti-myosin antibody (Sigma) diluted in an antibody diluent ( $\mathrm{pH} 8.0$, DAKO) at 1:20 dilution, and were incubated with the antibody (goat anti-mouse IgG conjugated with $10 \mathrm{~nm}$ gold [no. EM.GMHL10, Polysciences]) diluted 1:50 in the antibody diluent for $1.5 \mathrm{~h}$ at the same temperature. Next, the above procedure was repeated for rabbit polyclonal antibody to kinesin diluted in an antibody diluent $(\mathrm{pH} \mathrm{8.0,}$ DAKO) at a 1:20 dilution, and incubated with the final antibody (goat anti-rabbit $\mathrm{IgG}$ conjugated with $20 \mathrm{~nm}$ gold [no. EM.GAR20, Polysciences]) diluted 1:70 in the antibody diluent for $1.5 \mathrm{~h}$ at the same temperature.

\section{Western blot technique}

Proteins from ovary epidermis were extracted according to Wang et al. (2006) and then fractionated on 3-8\% NuPAGE Novex Tris-Acetate gels and blotted onto Nitrocellulose Membrane $0.45 \mu \mathrm{m}$ pore size (Invitrogen). O. umbellatum motor proteins: kinesin, myosin and dynein were detected with the rabbit polyclonal anti-kinesin antibody (Thermo Scientific), mouse monoclonal anti-myosin antibody (Sigma) and goat polyclonal anti-dynein antibody (Santa Cruz Biotechnology) diluted 1:50 (kinesin) and 1:200 (myosin and dynein) using Chromogenic Western Blot Immunodetection Kit (Invitrogen). Instead of the primary antibody, non-immune goat serum at the same concentration as the specific antibody was used as the control.

Analysis of protein extracts of $O$. umbellatum ovary epidermis regarding the presence of dynein heavy chains was carried out in Mass Spectrometry Laboratory, Institute of Biochemistry and Biophysics, PAS, Warszawa, Poland.

\section{Statistics}

To estimate the percentage of kinesin and myosin as potential motor proteins in lipotubuloids, the number of gold grains was estimated for: (1) kinesin and myosin appearing separately, (2) colocalization of both proteins cooperating with a single microtubule and (3) kinesin and myosin adjacent to heterodimers. The sum of gold grains for the above-mentioned items was taken as $100 \%$. Micrographs of 30 lipotubuloids from different epidermal cells of $O$. umbellatum ovary were analyzed.

\section{Results}

Character of intracellular movement in O. umbellatum ovary epidermis

Figure 1 shows a drawing of a living epidermis cell presented in a phase contrast (a), and of a lipotubuloid as it 
Fig. 1 Fragment of a living epidermis cell of $O$. umbellatum ovary: a drawing of a cell in a phase contrast with a lipotubuloid which turned around several times during 10-12 s, changing direction and axis of rotary motion; long arrows - the direction of lipotubuloid rotation, short arrows-direction of cytoplasm movement; b lipotubuloid as it was seen in EM (Kwiatkowska 1972, modified); $g$ Golgi apparatus, $l b$ lipid body, $m$ mitochondrion, $n$ nucleus, $v$ vacuole

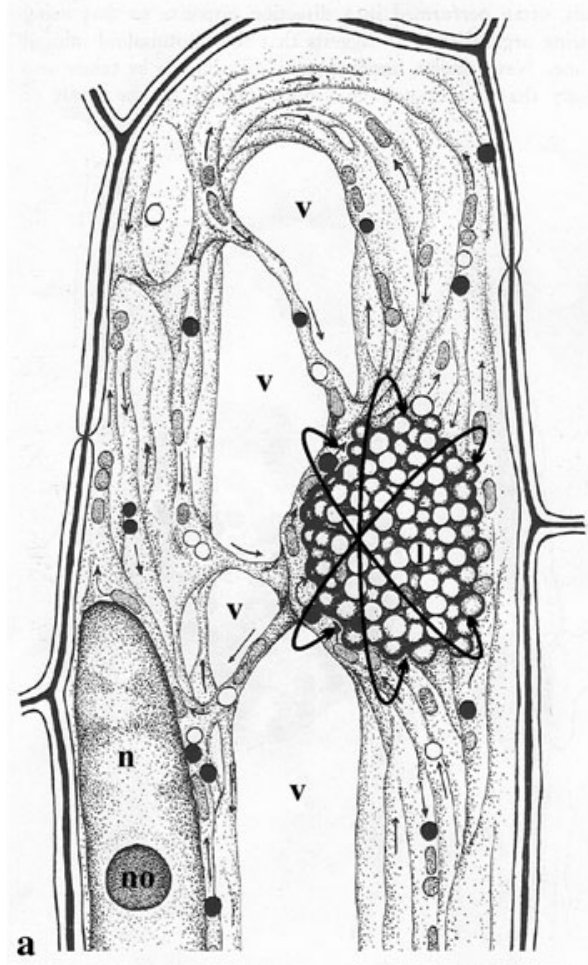

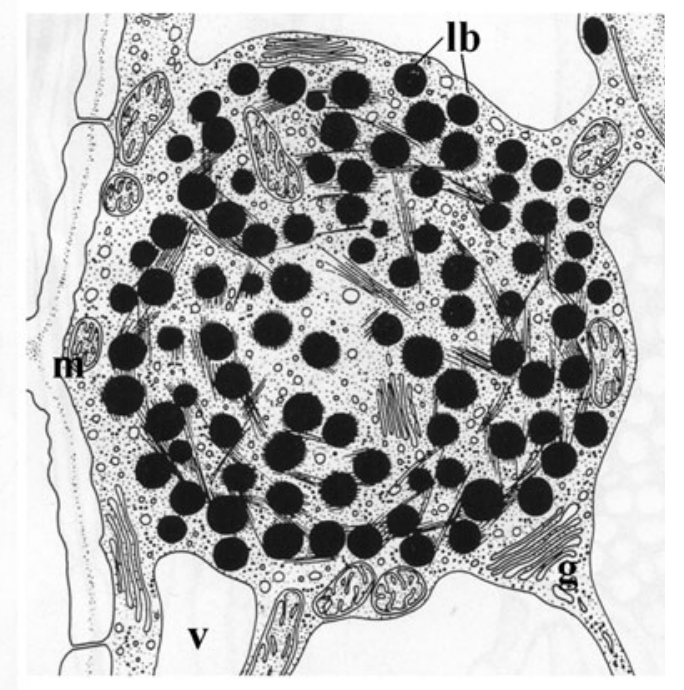

b was seen in EM (b). Progressive movement of a lipotubuloid in an epidermis cell is presented in Fig. 2a-d. As can be seen in Fig. 2a, the lipotubuloid passes along a cell wall in adjacent cytoplasm but it can also move in a cytoplasm strand, reach the opposite wall, change direction or stop for some time in different parts of a cell, most often near a nucleus (Fig. 2b-d). Rotations of a lipotubuloid accompany progression or may appear when it stops in different places inside a cell. Lipotubuloid rotations can be very dynamic with peripheral rotary speed from 5.2 to $31.4 \mu \mathrm{m} / \mathrm{s}$ (this is 6.2 -fold faster than the maximum rotary speed of the cytoplasm in epidermis cells), they can change direction, rotation axis and speed.

Lipotubuloid motor proteins

\section{Kinesin localization}

Specificity of the antibody used for detection of kinesin was confirmed with the Western blot method which revealed the presence of a specific band of about $360 \mathrm{kDa}$ (Fig. 3a).

10-nm gold grains indicating kinesin were localized near microtubule walls which were best visible on microtubule cross sections (Fig. 3b, c); sometimes two grains were localized at opposite sides of a microtubule. On longitudinal sections of microtubules, 3-5 gold grains were aligned at each side of an actin filament localized between two microtubules (Fig. 3d, e). Actin filaments parallel to

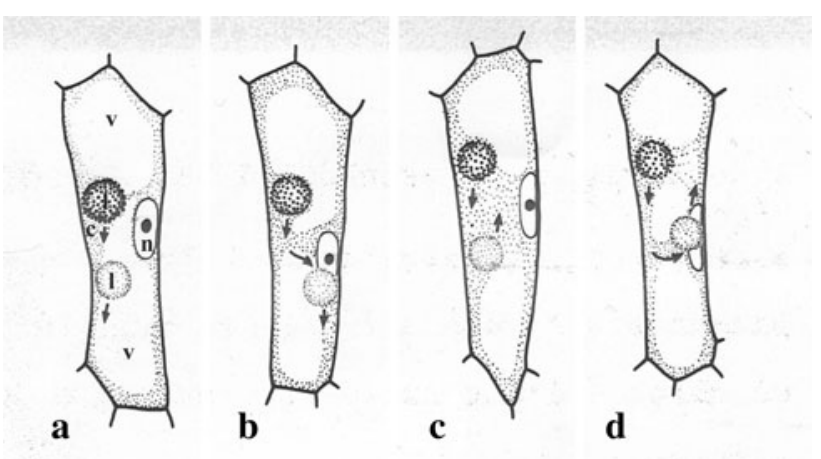

Fig. 2 Progressive movement of lipotubuloids in epidermis cellsschematic picture; $c$ cytoplasm, $l$ lipotubuloid, $n$ nucleus, $v$ vacuole, arrows indicate direction of lipotubuloid movement

microtubules were much better visible in preparations not treated with $\mathrm{H}_{2} \mathrm{O}_{2}$ (Fig. 4a, b), which is used to unmask the receptors of the tested substances in the immunogold technique. Immunosignals indicating kinesin presence were unevenly dispersed near lipotubuloid microtubules. Their localization indicated that they joined actin filaments and microtubules.

\section{Myosin localization}

Specificity of the antibody was confirmed with the Western blot method which revealed the presence of one specific band of about $20 \mathrm{kDa}$ (Fig. 5a). 
Fig. 3 Detection of kinesin: a Western blot analysis; line 1-SDS-PAGE electrophoretic separation of the epidermis cell extract; line 2-pre-immune serum; line 3-Western blotting of the epidermis cell extract probed with the anti-kinesin antibody; line 4-molecular mass standards and their weights in $\mathrm{kDa}$; *Proteins revealed (b-f) immunogold localization; $10-\mathrm{nm}$ gold grains near microtubule walls in the cross sections (b-d) and in longitunal sections at each side of an actin filament (short white arrow) placed between two microtubules $(\mathbf{e}, \mathbf{f})$ with schemes of kinesin connection with microtubules $(\mathbf{b}, \mathbf{f}) ; m t$ microtubules, $B a r=50 \mathrm{~nm}$

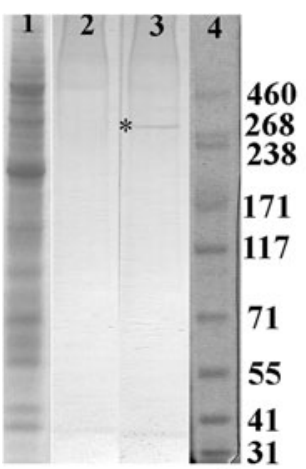

a

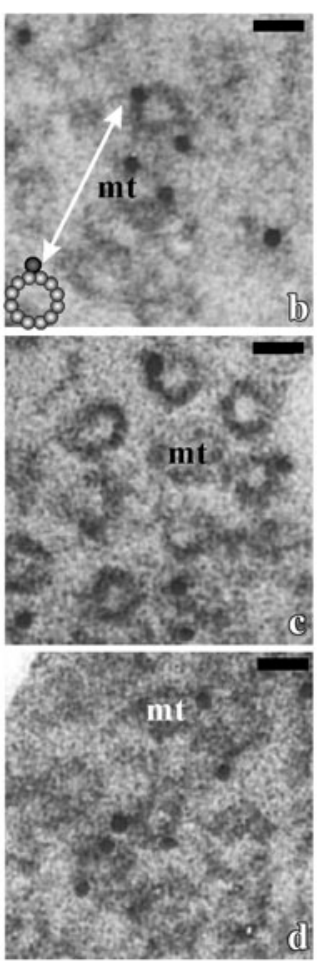

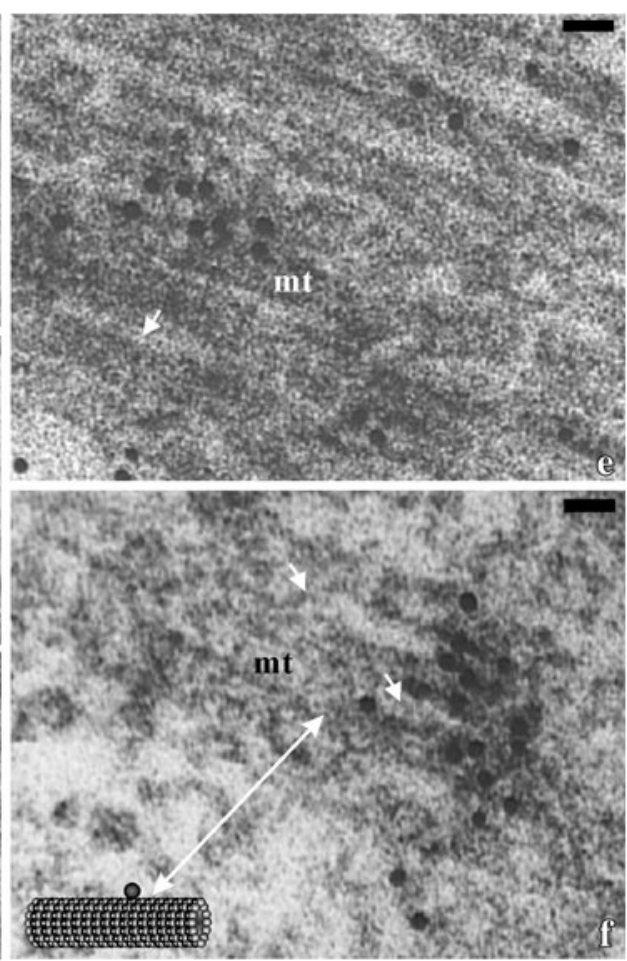

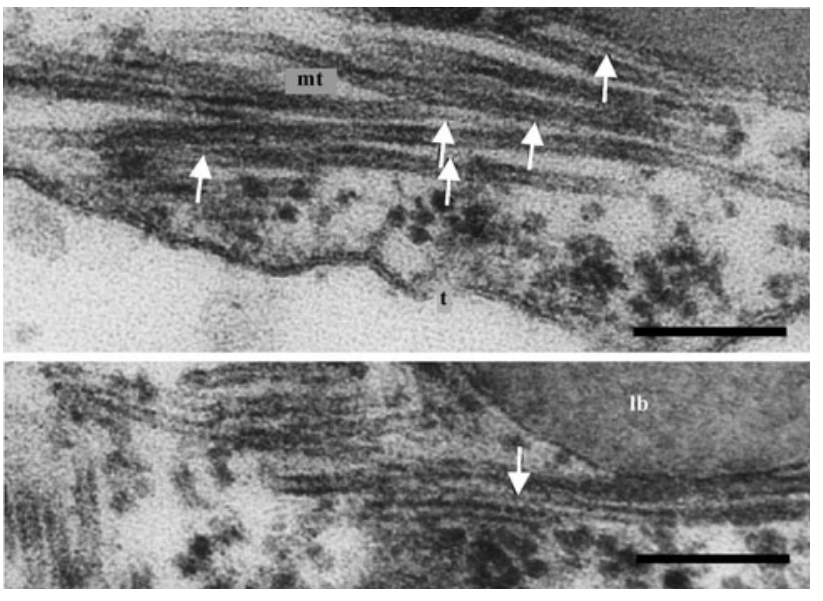

Fig. 4 Microtubules and actin filaments (arrows) in a lipotubuloid of $O$. umbellatum ovary epidermis; $l b$ lipid bodies, $m t$ microtubules, $t$ tonoplast, $B a r=0.1 \mu \mathrm{m}$

20-nm gold grains indicating myosin were localized between two microtubules in a lipotubuloid mostly separately (Fig. 5b, c) or in couples at opposite sides of microfilaments (Fig. 5d, e). They were also visible between cross-sectioned microtubules (Fig. 5d, e). Similarly as kinesin, myosin joined actin filaments with microtubules.

Figure 6 shows a dictyosome of Golgi apparatus in a lipotubuloid (comp. Fig. 1b) which was labeled with gold grains indicating the presence of myosin near cisternae membranes at each side of a dictyosome or near a middle cisternae.
Double labeling immunogold test for kinesin and myosin

The results of the double-immunogold test for myosin (10-nm grains) and for kinesin (20-nm grains) evidence that both motor proteins can be bound to the same microtubule ( $9 \%$ of total labeling) (Fig. 7a-c). Sometimes 10-nm and 20-nm gold grains were joined together which probably means that myosin and kinesin may form an integrated motor ( $8 \%$ of total labeling) (Fig. 7d). Labeling for kinesin and myosin alone accounts for 54 and $29 \%$ of the total labeling, respectively.

The fact that microtubules and actin filaments appeared close to one another (Fig. 4) as well as co-localization of gold grains indicating the presence of kinesin and myosin near microtubules (Fig. 7) enabled us to propose models of co-operations between these motor proteins and cytoskeleton filaments in lipotubuloid (Fig. 8).

\section{Localization of dynein light chains}

Specificity of the antibody used for detection of dynein light chains was confirmed with the Western blot method which revealed the presence of a specific band of about $14 \mathrm{kDa}$ (Fig. 9a). In lipotubuloids, immunosignals demonstrating localization of dynein light chains were visible in dictyosomes, as well as on lipid bodies periphery, in microtubules and cytoplasm (Fig. 9b, c).

Since analysis of proteins separated in polyacrylamide gel using spectroscopy mass method (Mass Spectrometry 
Fig. 5 Detection of myosin: a Western blot analysis line 1-SDS-PAGE electrophoretic separation of the epidermis cell extract; line 2-pre-immune serum, line 3-Western blotting of the epidermis cell extract probed with the anti-myosin antibody; line 4-molecular mass standards and their weights in $\mathrm{kDa}$; *Proteins revealed $(\mathbf{b}-\mathbf{e})$ immunogold localization; 20-nm grains near microtubules in longitudinal section (b-d) and cross-section (e); $m t$ microtubules;

Bar $=50 \mathrm{~nm}$
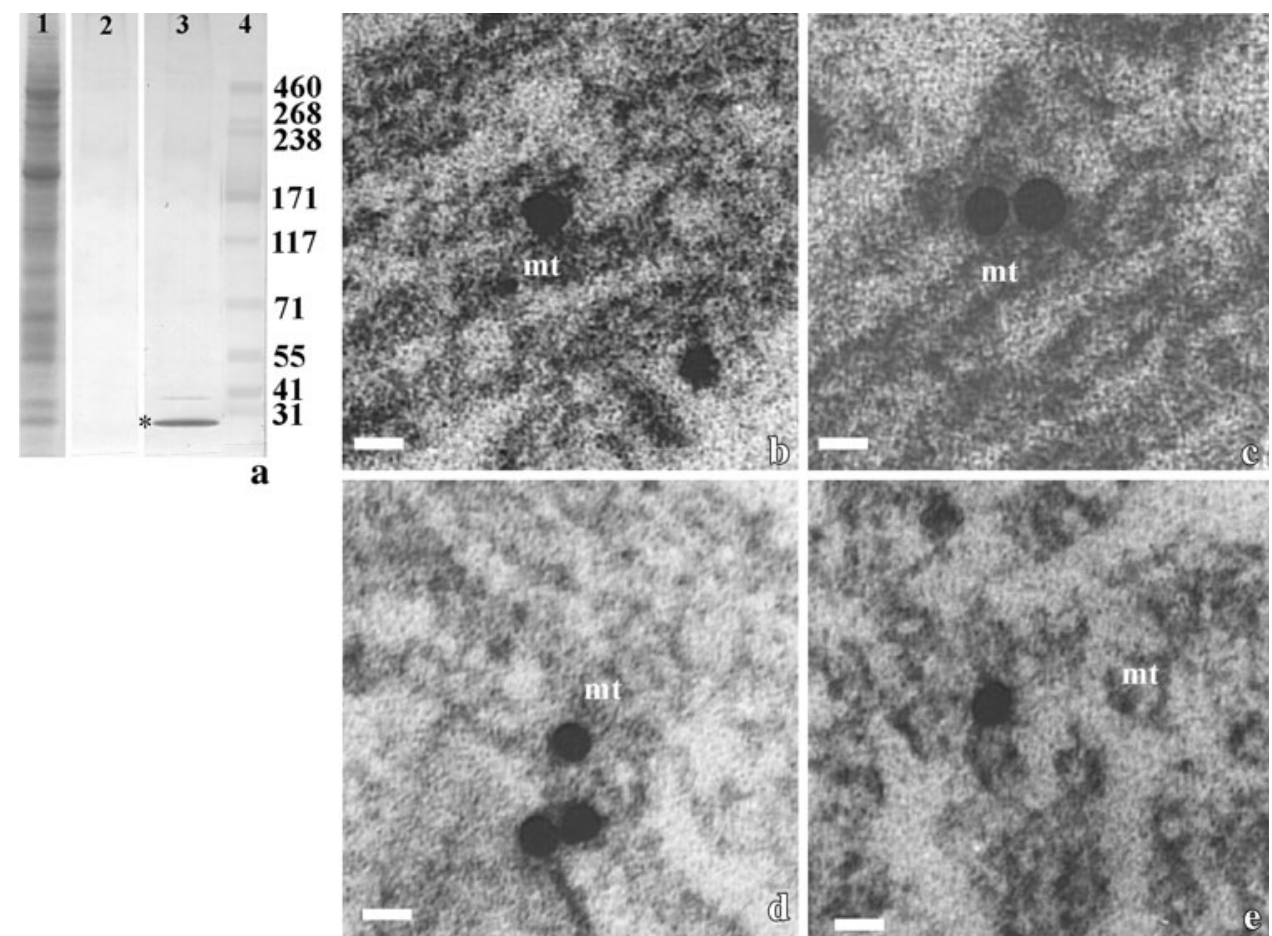

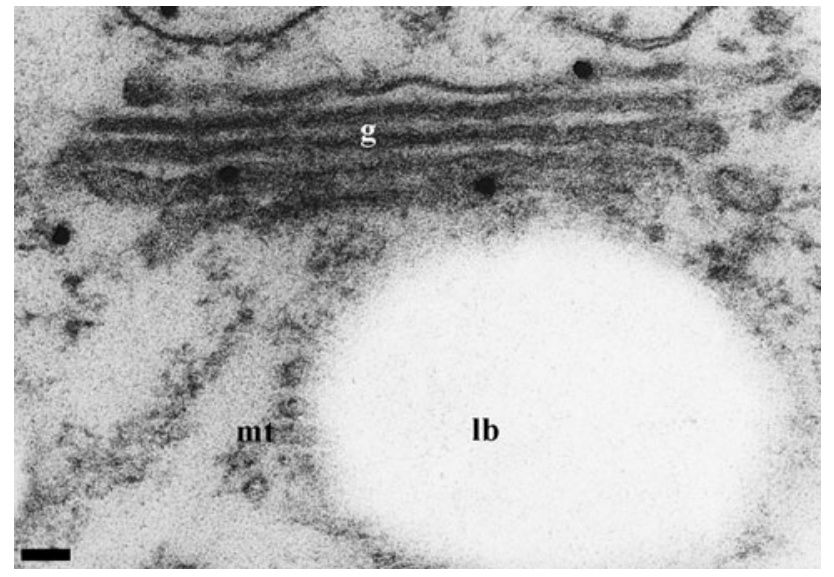

Fig. 6 20-nm gold grains demonstrating myosin presence in Golgi structure of $O$. umbellatum lipotubuloid; $g$ Golgi apparatus, $l b$ lipid bodies, $m t$ microtubules; $B a r=100 \mathrm{~nm}$

Laboratory, Institute of Biochemistry and Biophysics, PAS, Warszawa, Poland) did not reveal heavy chains of dynein, light chains were not connected with lipotubuloid movement but with other functions.

\section{Discussion}

The presence of motor proteins, kinesin and myosin, revealed with the immunogold method in this researches closely corresponds with earlier findings regarding the characteristic lipotubuloid movement (Kwiatkowska 1972; Kwiatkowska et al. 2006, 2009). The activity of both motor proteins together with two cytoskeletal elements, microtubules and actin filaments, seems to be the driving force generating specific, variable, very dynamic and complex, autonomic rotation of lipotubuloids which depends on ATP (which was proved by the experiments with DNP); according to Gunning and Hardham (1982), it is unique to cells.

Direct interactions between actin filaments and microtubules through motor proteins are found in eukaryotic cells but to date they have not been demonstrated with the immunogold technique. Kinesin and myosin interact with microtubules and actin filaments, respectively. Alternatively, myosin and kinesin motors interact to create an integrated motor, which uses both actin filaments and microtubules as a transport track (Petrášek and Schwarzerowá 2009). Although all types of interactions were described in animal organisms, to date only kinesin-mediated interaction between microtubules and actin filaments was identified in plants (Preuss et al. 2004; Xu et al. 2009; Klotz and Nick 2012). The fact that our observations demonstrated that both myosins and kinesins connected actin filaments with microtubules is innovatory.

In general, motors do not work in isolation but in a group (Guérin et al. 2010). Using single-molecule in vitro techniques, Ali et al. (2008) showed that a functional consequence of myosin V's diffusion on microtubules was a significant enhancement of the processive run length of kinesin when both motors were present on the same cargo. The electrostatic interaction of myosin $\mathrm{V}$ with microtubules increases the processivity of kinesin. Thus, we 
Fig. 7 Double immunogold localization of myosin (10-nm grains) and kinesin (20-nm grains) connected with microtubules: a longitudinalsectioned (black arrow) and b-d cross-sectioned microtubules (white arrows); both grains $\mathbf{d}$ lie close together; Bar $=50 \mathrm{~nm}$
Fig. 8 Models of motor protein connections with microtubules; a kinesin connects microtubules with actin filaments, b kinesin and myosin connect microtubules with actin filaments, $\mathbf{c}, \mathbf{d}$ two types of connections of kinesin and myosin with a microtubule (a microtubule cross section). Scheme prepared on the basis of current micrographs and papers: Goode et al. (2000), Rodriguez et al. (2003), Schroeder et al. (2010)
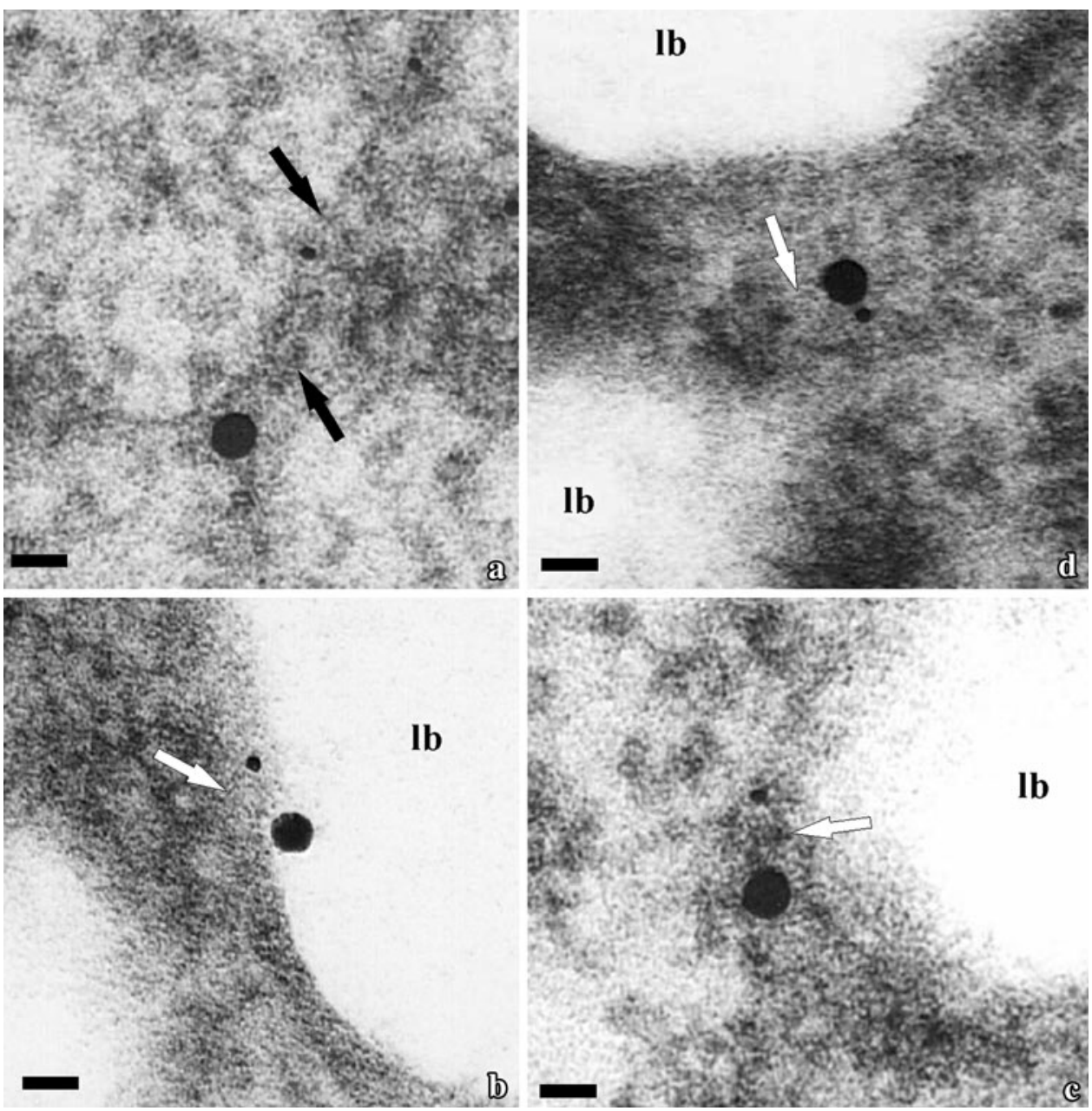
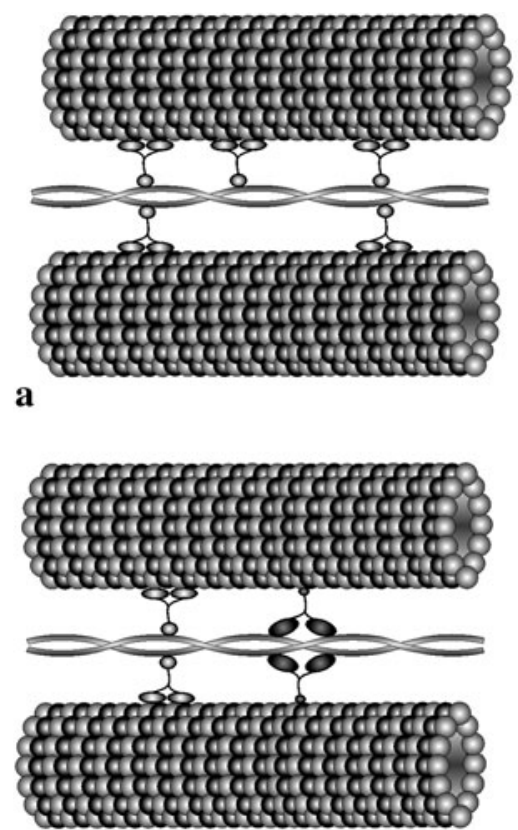

b 
Fig. 9 Detection of light chains of dynein: a Western blot analysis: line 1 -SDS-PAGE electrophoretic separation of the epidermis cell extract; line 2-pre-immune serum; line 3 -Western blotting of the epidermis cell extract probed with the anti-dynein light chain antibody; line 4-molecular mass standards and their weights in $\mathrm{kDa}$; * Proteins revealed; b immunogold studies demonstrating presence of light chains of dynein in Golgi structure and $\mathbf{c}$ in lipid bodies and cytoplasm; $g$ Golgi apparatus, $l b$ lipid bodies, white arrow-cross section of microtubules; $B a r=100 \mathrm{~nm}$
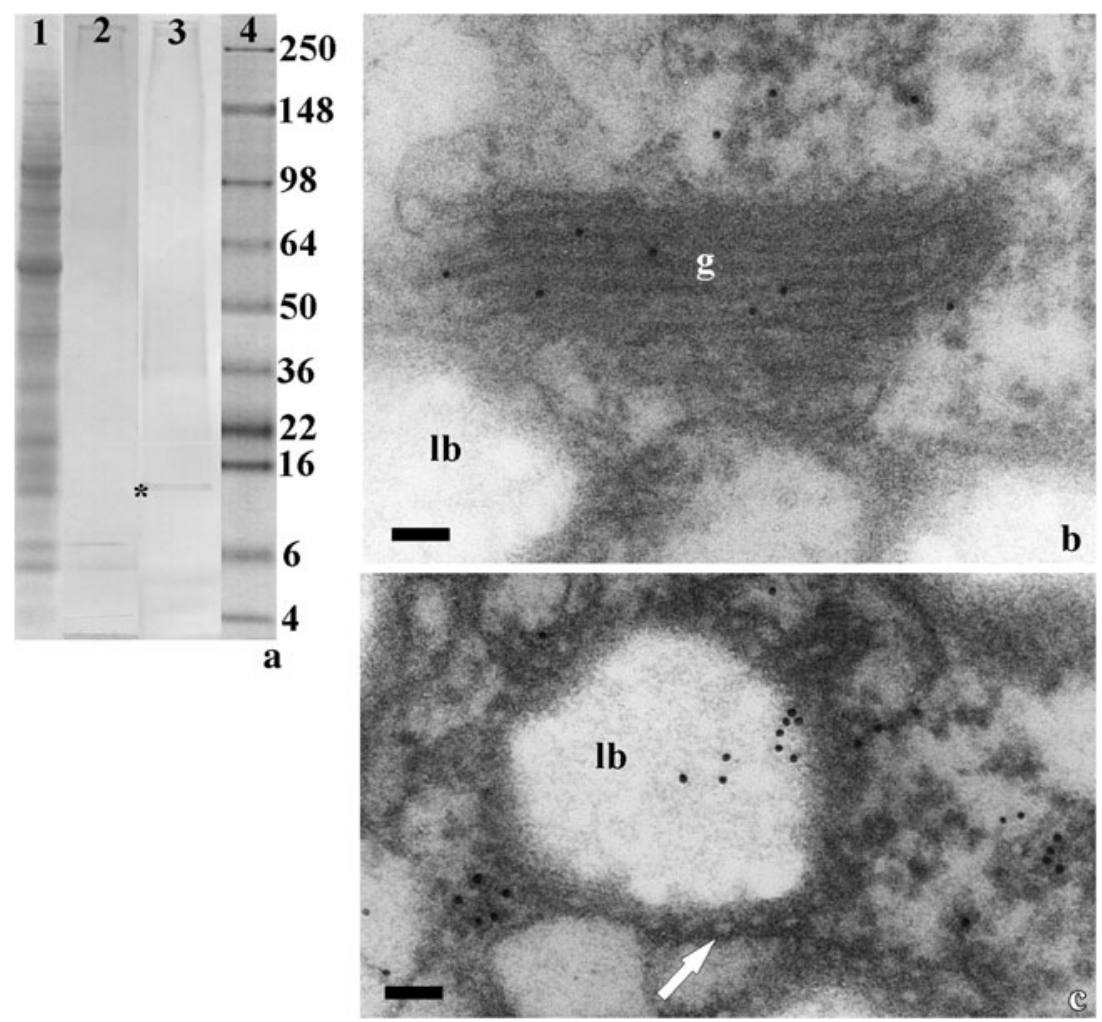

suppose that the presence of both kinesin and myosin connected with the same microtubules and actin filaments might mutually enhance their motor activity making a lipotubuloid rotate with the speed up to $31.4 \mu \mathrm{m} / \mathrm{s}$, i.e. 6-fold greater than that of cyclosis (Kwiatkowska 1972).

Our earlier studies on lipotubuloid movement in $O$. umbellatum revealed that in a vigorously rotating lipotubuloid microtubules exhibited different widths or diameters on longitudinal (Kwiatkowska 1972) or cross (Kwiatkowska et al. 2009) sections, respectively. The use of $\mathrm{OsO}_{4}$ for direct fixation of microtubules, due to its quick penetration, allowed to maintain their structure identical to that observed in vivo (Omoto and Kung 1980). Differences in size were even visible in the microtubules consisting of the same number of protofilaments (Kwiatkowska et al. 2009). In such a case, two subpopulations of microtubules differing in diameters, were observed while after blocking the movement with DNP only one population of microtubules with medium-size diameters was present. Upon DNP removal, the two populations reappeared and rotation of lipotubuloids was restored. Analysis of the structure of microtubule walls on the cross sections varying in diameter showed that the differences resulted from different distances between neighboring protofilaments and from the degree of expansion or compression of tubulin units (Kwiatkowska et al. 2006, 2009). A hypothesis has been put forward that changes in microtubule diameter
(Kwiatkowska et al. 2006, 2009) might be connected with the driving force of lipotubuloid movement.

Cao et al. (2004) revealed that in vitro co-sedimentation of microtubules, actin filaments and myosin-Va resulted in microtubules with varying widths, simultaneously myosinVa bound actin filaments with microtubules. In lipotubuloids, myosin and kinesin also connected microtubules and microfilaments. It seems possible that motor proteins together with actin filaments may drive lipotubuloid rotation changing microtubule conformation, i.e. making narrow ones wide and vice versa.

Flexibility of microtubules connected with the fact that microtubule subunits are bound more strongly inter-protofilaments than within-protofilaments in vitro was shown by many authors (Chrétien et al. 1998; Nogales 1999; Nogales et al. 1999; Löwe et al. 2001; Meurer-Grob et al. 2001; Kis et al. 2002; Sept et al. 2003; Krebs et al. 2005; Tuszyński et al. 2005; Wang and Nogales 2005; Nogales and Wang 2006; Drabik et al. 2007; Hunyadi and Jánosi 2007).

It seems obvious that the progressive-rotary movement of lipotubuloids is crucial for the functioning of epidermis cells which exhibit very active, 30-fold growth during ovary development and its transformation into a fruit. These processes are correlated with DNA endoreduplication and lipotubuloid activity as well as they are regulated by gibberellins (Kwiatkowska et al. 2007, 2011b). 
The way a lipotubuloid moves in a cell (see Fig. 2) suggests that this movement is not accidental but is controlled by signals from a cell directing this lipotubuloid to the site, where nutrients and cuticle building blocks are most necessary (Kwiatkowska et al. 2012). It seems possible since microtubules and actin filaments play a receptor-like role for Rho proteins which are involved in many important biological processes, e.g. cell growth (Mucha et al. 2011). Recently, formation of wide microtubules, "macrotubules" was found in plant cells under changing level of reactive oxygen species (ROS) which function as signaling molecules (Livanos et al. 2012).

Phospholipase D (PLD) is another element involved in cytoskeleton-mediated signaling (Ho et al. 2009). Gold grains decorating microtubules which indicate the presence of PLD were observed with the immunogold technique in $O$. umbellatum lipotubuloids (Kwiatkowska et al. 2012)

The progressive-rotary movement undoubtedly enables intensive transport of components present in lipotubuloid lipid bodies into epidermis cells and cuticle. Cytoplasmic flow accelerates the distribution rate of soluble materials in relation to the slow rate of diffusion (Esseling-Ozdoba et al. 2008). This is supported by the results concerning the involvement of intracellular motion in spreading various substances in a cell (Verchot-Lubicz and Goldstein 2010).

The latest autoradiographic and immunocytochemical research revealed that lipids synthesized in lipotubuloids were stored in them only for some time. On the surface of lipotubuloid lipid bodies, similarly as of lipid droplets in oleate-loaded COS-7-cells (Kuerschner et al. 2008; Stone et al. 2009) in macrophages (Buers et al. 2009) and murine cells (McFie et al. 2011) there is DGAT2. This enzyme is involved in triacylglyceride synthesis which was evidenced by autoradiographic studies with ${ }^{3} \mathrm{H}$-palmitic acid which is incorporated into the surface layer of lipotubuloid lipid bodies (Kwiatkowska et al. 2012). Lipids forming in them became lipolyzed by lipase and the resulting products were transported out of a lipotubuloid into cytoplasm and following appropriate biochemical reactions were deposited into cuticle (Kwiatkowska et al. 2011b).

The presence of dynein light chains, which was revealed in lipotubuloids with the immunogold technique, is another interesting issue. However, it is not connected with a cell and lipotubuloid movement. Dynein light chain coding genes are present in all eukaryotic genomes, they code extremely conservative $10 \mathrm{kDa}$ proteins (Pfister et al. 2006). Lack of dynein heavy chains observed in Western blot indicates that in $O$. umbellatum lipotubuloids dynein light chains did not form dynein. They are core elements of eukaryotic cells probably binding with hundreds of proteins (Rapali et al. 2011). The presence of dynein light chain molecules in fibroblast Golgi structures (Tai et al. 1998) support our observations reaviling them by immunogold method as gold grains in lipotubuloid Golgi structures. Other authors believe that Golgi structure movements depend on myosin XI (Avisar et al. 2009, 2012). The latter idea is in agreement with our finding showing gold grains, thus indicating myosin presence in Golgi cisternae. A hypothesis can be put forward that dictyosomes move within a lipotubuloid, being a set of cooperating organelles, which plays a key role in $O$. umbellatum ovary epidermis development (Kwiatkowska et al. 2012).

Author contribution M. Kwiatkowska designed the experiments and prepared manuscript, J.T. Polit designed scheme of the figure in manuscript, K. Popłońska prepared figures, D. Stępiński was involved in English version preparation of manuscript, A. Wojtczak made immunogold analysis. All the authors were responsible for experimental part and writing the manuscript.

Acknowledgments This work was realized and financed by National Committee of Scientific Research, grant no NN 303359035.

Open Access This article is distributed under the terms of the Creative Commons Attribution License which permits any use, distribution, and reproduction in any medium, provided the original author(s) and the source are credited.

\section{References}

Ali MY, Lu H, Bookwalter CS, Warshaw DM, Trybus KM (2008) Myosin V and kinesin act as tethers to enhance each others' processivity. Proc Natl Acad Sci USA 105:4691-4696

Avisar D, Abu-Abied M, Belausov E, Sadot E, Hawes Ch, Sparkes IA (2009) A comparative study of the involvement of 17 Arabidopsis myosin family members on the motility of Golgi and other organelles. Plant Physiol 150:700-709

Avisar D, Abu-Abied M, Belausov E, Sadot E (2012) Myosin XIK is a major player in cytoplasm dynamics and its regulated by two amino acids in its tail. J Exp Bot 63:241-249

Bendayan M, Zollinger M (1983) Ultrastructural localization of antigenic sites on osmium-fixed tissues applying the protein A-gold technique. J Histochem Cytochem 31:101-109

Brozzi F, Diraison F, Lajus S, Rajatileka S, Philips T, Regazzi R, Fukuda M, Verkade P, Molnár E, Váradi A (2012) Molecular mechanism of myosin $\mathrm{Va}$ recruitment to dense core secretory granules. Traffic 13:54-69

Buers I, Robenek H, Lorkowski S, Nitsche Y, Severs NJ, Hofnagel O (2009) TIP47, a lipid cargo protein involved in macrophage triglyceride metabolism. Arterioscl Throm Vas 29:767-773

Cao TT, Chang W, Masters SE, Mooseker MS (2004) Myosin-Va binds to and mechanochemically couples microtubules to actin filaments. Mol Biol Cell 15:151-161

Chrétien D, Flyvbierg H, Fuller SD (1998) Limited flexibility of the inter-protofilament bonds in microtubules assemble from pure tubulin. Eur Biophys J 27:490-500

Collings D (2009) Twisting to a different rhythm: how plants have used conserved microtubules for plant-specific functions. Aust Biochem 40:14-18

Collings DA, Lill AW, Himmelspach R, Wasteneys GO (2006) Hypersensivity to cytoskeletal antagonists demonstrates 
microtubule-microfilament cross-talk in the control of root elongation in Arabidopsis thaliana. New Phytol 170:275-290

Drabik P, Gusarov S, Kovalenko A (2007) Microtubule stability studied by three-dimensional molecular theory of salvation. Biophys J 92:394-403

Esseling-Ozdoba A, Houtman D, van Lammeren AA, Eiser E, Emons AM (2008) Hydrodynamic flow in the cytoplasm of plant cells. J Microsc 231:274-283

Faulk WP, Taylor GM (1971) An immunocolloid method for the electron microscope. Immunochemistry 8:1081-1083

Frey N, Klotz J, Nick P (2009) Dynamic bridges-a calponin-domain kinesin from rice links actin filaments and microtubules in both cycling and non-cycling cells. Plant Cell Physiol 50:143-1506

Goode BL, Drubin DG, Barnes G (2000) Functional cooperation between the microtubule and actin cytoskeletons. Curr Opin Cell Biol 12:63-71

Guérin T, Prost J, Martin P, Joanny J-F (2010) Coordination and collective properties of molecular motors: theory. Curr Opin Cell Biol 22:14-20

Gunning BES, Hardham AR (1982) Microtubules. Annu Rev Plant Physiol 33:651-698

Ho AYY, Day DD, Brown MH, Marc J (2009) Arabidopsis phospholipase Dõ as an initiator of cytoskeleton-mediated signaling to fundamental cellular processes. Funct Plant Biol 36:190-198

Huang J-D, Brady ST, Richards BW, Stenoien D, Resau JH, Copeland NG, Jenkins NA (1999) Direct interaction of microtubule- and actin-based transport motors. Nature 397:267-270

Huang S, Jin L, Du J, Lin H, Zhao Q, Ao G, Yuan M (2007) SB401, a pollen-specific protein from Solanum berthaultii, binds to and bundles microtubules and F-actin. Plant J 51:406-418

Hunyadi V, Jánosi IM (2007) Metastability of microtubules induced by competing internal forces. Biophys J 92:3092-3097

King SM (2002) Dyneins motor on in plants. Traffic 3:930-931

Kis A, Kasas S, Babić B, Kulik AJ, Benoit W, Briggs GAD, Schönenberger C, Catsicas S, Forró L (2002) Nanomechanics of microtubules. Phys Rev Lett 89:248101

Klotz J, Nick P (2012) A novel actin-microtubule cross-linking kinesin, $\mathrm{NtKCH}$, functions in cell expansion and division. New Phytol 193:576-589

Krebs A, Goldie KN, Hoenger A (2005) Structural rearrangement in tubulin following microtubule formation. EMBO Rep 6:227-232

Kuerschner L, Moessinger C, Thiele C (2008) Imaging of lipid biosynthesis: how a neutral lipid enters lipid droplets. Traffic 9:338-352

Kunda P, Baum B (2009) The actin cytoskeleton in spindle assembly and positioning. Trends Cell Biol 19:174-179

Kwiatkowska M (1972) Changes in the diameter of microtubules connected with the autonomous rotary motion of the lipotubuloids (elaioplasts). Protoplasma 75:345-357

Kwiatkowska M, Popłońska K, Stępiński D (2005) Actin filaments connected with microtubules of lipotubuloids-cytoplasmic domains rich in lipid bodies and microtubules. Protoplasma 226:163-167

Kwiatkowska M, Popłońska K, Stępiński D, Hejnowicz Z (2006) Microtubules with different diameter, protofilament number and protofilament spacing in $O$. umbellatum ovary epidermis cells. Folia Histochem Cytobiol 44:133-138

Kwiatkowska M, Popłońska K, Kaźmierczak A, Stępiński D, Rogala K, Polewczyk K (2007) Role of DNA endoreduplication, lipotubuloids, gibberellic acid in epidermal cell growth during fruit development of $O$. umbellatum. J Exp Bot 58:2023-2031

Kwiatkowska M, Stępiński D, Popłońska K (2009) Diameters of microtubules change during rotation of the lipotubuloids of Ornithogalum umbellatum stipule epidermis as a result of varying protofilament monomers sizes and distance between them. Cell Biol Int 33:1245-1252
Kwiatkowska M, Stępiński D, Popłońska K, Wojtczak A, Polit JT (2010) "Elaioplasts" of Haemanthus albiflos are true lipotubuloids - cytoplasmic domains rich in lipid bodies entwined by microtubules. Acta Physiol Plant 32:1189-1196

Kwiatkowska M, Stępiński D, Popłońska K, Wojtczak A, Polit JT (2011a) "Elaioplasts" identified as lipotubuloids in Althaea rosea, Funkia Sieboldiana and Vanilla planifolia contain lipid bodies connected with microtubules. Acta Soc Bot Pol 80:211219

Kwiatkowska M, Popłońska K, Polit JT, Wojtczak A, Stępiński D, Paszak K (2011b) Lipid bodies in lipotubuloids of Ornithogalum umbellatum ovary epidermis contain diacylglycerol acyltransferase 2 (DGAT2) and lipase, incorporate ${ }^{3} \mathrm{H}$-palmitic acid and are connected with cuticle synthesis. Trends Cell Mol Biol 6:97-108

Kwiatkowska M, Popłońska K, Wojtczak A, Stępiński D (2012) Lipid body biogenesis and the role of microtubules in lipid synthesis in Ornithogalum umbellatum lipotubuloids. Cell Biol Int 36:455462

Lam SK, Cai Y, Hillmer S, Robinson DG, Jiang L (2008) SCAMPs highlight the developing cell plate during cytokinesis in tobacco BY-2 cells. Plant Physiol 147:1637-1645

Lawrence CJ, Morris NR, Meagher RB, Dawe RK (2001) Dyneins have run their course in plant lineage. Traffic 2:362-363

Lee Y-R, Liu B (2004) Cytoskeletal motors in Arabidopsis. Sixty-one kinesins and seventeen myosins. Plant Physiol 136:3877-3883

Lenartowska M, Isaji M, Miller KG (2012) A pre-embedding immunogold approach reveals localization of myosin VI at the ultrastructural level in the actin cones that mediate Drosophila spermatid individualization. Protoplasma 249:337-346

Li Y, Shen Y, Cai C, Zhong C, Zhu L, Yuan M, Ren H (2010) The type II Arabidopsis formin 14 interacts with microtubules and microfilaments to regulate cell division. Plant Cell 22:2710 2726

Livanos P, Galatis B, Quader H, Apostolakos P (2012) Disturbance of reactive oxygen species homeostasis induces atypical tubulin polymer formation and affects mitosis in root-tip cells of Triticum turgidum and Arabidopsis thaliana. Cytoskeleton 69:1-21

Loubéry S, Delevoye C, Louvard D, Raposo G, Coudrier E (2012) Myosin VI regulates actin dynamics and melanosome biogenesis. Traffic 13:665-680

Löwe J, Li H, Downing KH, Nogales E (2001) Refined structure of $\alpha \beta$-tubulin at 3.5 $\AA$ resolution. J Mol Biol 313:1045-1057

McFie PJ, Banman SL, Kary S, Stone SJ (2011) Murine diacylglycerol acyltransferase-2 (DGAT2) can catalyze triacylglycerol synthesis and promote lipid droplet formation independent of its localization to the endoplasmic reticulum. J Biol Chem 286: 28235-28246

Meurer-Grob P, Kasparian J, Wade RH (2001) Microtubule structure at improved resolution. Biochemistry 40:8000-8008

Mucha E, Fricke I, Schaefer A, Wittinghofer A, Berken A (2011) Rho proteins of plants- functional cycle and regulation of cytoskeletal dynamics. Eur J Cell Biol 90:934-943

Nakata T, Niwa S, Okada Y, Perez F, Hirokawa N (2011) Preferential binding of a kinesin-1 motor to GTP-tubulin-rich microtubules underlies polarized vesicle transport. J Cell Biol 194:245-255

Nogales EA (1999) Structural view of microtubule dynamics. Cell Mol Life Sci 56:133-142

Nogales E, Wang HW (2006) Structural intermediates in microtubule assembly and disassembly how and why? Curr Opin Cell Biol 18:179-184

Nogales E, Whittaker M, Milligan RA, Downing KH (1999) Highresolution model of the microtubule. Cell 96:79-88

Oelkers JM, Vinzenz M, Nemethova M, Jakob S, Lai FPL, Block J, Szczodrak M, Kerkhoff E, Backert S, Schlüter K, Stradal TEB, 
Small JV, Koestler SA, Rottner K (2011) Microtubules as platforms for assaying actin polymerization in vivo. PLOS ONE 6:e19931

Omoto CK, Kung C (1980) Rotation and twist of central-pair microtubules in the cilia of paramecium. J Cell Biol 87:33-46

Petrášek JP, Schwarzerowá K (2009) Actin and microtubule cytoskeleton interactions. Curr Opin Plant Biol 12:728-734

Pfister KK, Shah PR, Hummerich H, Russ A, Cotton J, Annuar AA, King SM, Fisher EMC (2006) Genetic analysis of the cytoplasmic dynein subunit families. PLoS Genet 2(1):e1

Preuss ML, Kovar DR, Lee Y-RJ, Staiger CJ, Delmer DP, Liu B (2004) A plant-specific kinesin binds to actin microfilaments and interacts with cortical microtubules in cotton fibers. Plant Physiol 136:3945-3955

Rapali P, Szenes A, Radnai L, Bakos A, Pal AG, Nyitray L (2011) DYNLL/LC8: a light chain subunit of dynein motor complex and beyond. FEBS J 278:2980-2996

Reynolds ES (1963) The use of lead citrate of high $\mathrm{pH}$ as an electronopaque stain in electron microscopy. J Cell Biol 17:208-212

Rodriguez OC, Schaefer AW, Mandato CA, Forscher P, Bement WM, Waterman-Storer CM (2003) Conserved microtubule-actin interactions in cell movement and morphogenesis. Nat Cell Biol 5:599-609

Romagnoli S, Cai G, Faleri C, Yokota E, Shimmen T, Cresti M (2007) Microtubule- and actin filament-dependent motors are distributed on pollen tube mitochondria and contribute differently to their movement. Plant Cell Physiol 48:345-361

Sainsbury F, Collings DA, Mackun K, Gardiner J, Hepler JDI, Marc J (2008) Developmental reorientation of transverse cortical microtubules to longitudinal directions: a role for actomyosin-based streaming and partial microtubule-membrane detachment. Plant J 56:116-131

Sampathkumar A, Lindeboom JJ, Debolt S, Gutierrez R, Ehrhardt DW, Ketelaar T, Persson S (2011) Live cell imaging reveals structural associations between the actin and microtubule cytoskeleton in Arabidopsis. Plant Cell. doi:10.1105/tpc.111.087940

Schroeder HW III, Mitchell C, Shuman H, Holzbaur ELF, Goldman YE (2010) Motor number controls cargo switching at actinmicrotubule intersections in vitro. Curr Biol 20:687-696
Sept D, Bakere NA, McCammon JA (2003) The physical basis of microtubule structure and stability. Protein Sci 12:2257-2261

Shanina NA, Lazareva EM, Skorova EY, Chentsov YS, Smirnova EA (2009) A high molecular weight polypeptide cross-reacting with the antibodies to the dynein heavy chain localizes to the subset to Golgi complex in higher plant cells. Cell Biol Int 33:290-300

Shevchenko GV (2009) Interaction of microtubules and microfilaments in the zone of distal elongation of Arabidopsis thaliana roots. Cytol Genet 43:223-229

Stone SJ, Levin MC, Zhou P, Han J, Walther TC, Farese RV Jr (2009) The endoplasmic reticulum enzyme DGAT2 is found in mitochondria-associated membranes and has a mitochondrial targeting signal that promotes its association with mitochondria. J Biol Chem 284:5352-5361

Tai AW, Chuang J-Z, Sung C-H (1998) Localization of Tctex-1, a cytoplasmic dynein light chain, to the Golgi apparatus and evidence for dynein complex heterogeneity. J Biol Chem 273:19639-19649

Tuszyński JA, Luchko T, Porter S, Dixon JM (2005) Anisotropic elastic properties of microtubules. Eur Phys J E 17:29-35

Verchot-Lubicz J, Goldstein RE (2010) Cytoplasmic streaming enables the distribution of molecules and vesicles in large cell. Protoplasma 240:99-107

Wang HW, Nogales E (2005) Nucleotide-dependent bending flexibility of tubulin regulates microtubule assembly. Nature 435: 911-915

Wang W, Vignani R, Scali M, Cresti M (2006) A universal and rapid protocol for protein extraction from recalcitrant plant tissues for proteomic analysis. Electrophoresis 27:2782-2786

Wei L, Zhang W, Liu Z, Li Y (2009) AtKinesin-13A is located on Golgi-associated vesicle and involved in vesicle formation/ budding in Arabidopsis root-cap peripheral cells. BMC Plant Biol 9:138. doi:10.1186/1471-2229-9-138

Xu T, Qu Z, Yang X, Qin X, Xiong J, Wang Y, Ren D, Liu G (2009) A cotton kinesin $\mathrm{GhKCH} 2$ interacts with both microtubules and microfilaments. Biochem J 421:171-180

Yasuda H, Kanda K, Koiwa H, Suenaga K, Kidou S, Ejiri S (2005) Localization of actin filaments on mitotic apparatus in tobacco BY-2 cells. Planta 222:118-129 